\title{
Why U.S. health care expenditure and ranking on health care indicators are so different from Canada's
}

\author{
A. H. G. M. Spithoven
}

Received: 31 July 2006 / Accepted: 6 June 2008 / Published online: 1 July 2008

(C) The Author(s) 2008

\begin{abstract}
Compared to other industrialized countries, the U.S. spends most of all on health care. Nonetheless, the U.S. ranks relatively low on health care indicators. This paradox has been already known for decades. For example, the turning point comparing the U.S. and Canada was in 1972. Health expenditure as a percentage of GDP was higher in Canada than in the USA from 1960 until 1972. Since 1972 expenditure on health care has been higher in the U.S. than in Canada (OECD 2005a, Health data 2005, fourteenth OECD electronic database on health systems, date of release June 2005, last update 04/26/2005). The present study integrates the dispersed literature on spending and health care rankings and adds some statistical analysis to these studies. The evaluation of different factors influencing health care expenditure in the U.S. relative to other countries is restricted to a comparison with Canada. The U.S. and Canada are two countries that are sufficiently similar to make comparisons useful. The comparison of factors influencing health care expenditure in the U.S. and Canada in 2002 reveals that health care expenditure in the U.S. is higher than in Canada mainly due to administration costs, Baumol's cost disease and pharmaceutical prices. It is not primarily inefficiency in health care production but the dominant prevalence for free choice and own responsibility that explains the paradox of high expenditure on health care and low ranking on health care indicators.
\end{abstract}

Keywords Health care expenditure · United States · Canada

JEL Classifications $\quad \mathrm{I} 10 \cdot \mathrm{I} 12$

\section{Introduction}

Health care outlays in the U.S. were equal to $14.6 \%$ of Gross Domestic Product (GDP) in 2002 (OECD 2005a). Compared to other industrialized countries, the U.S. had the highest spending

A. H. G. M. Spithoven ( $\varangle)$

Utrecht School of Economics, Janskerkhof 12, 3512 BL Utrecht, The Netherlands

e-mail: a.spithoven@econ.uu.nl 
on health care, even though 14\% of the population is uninsured in 2002 (NCHS 2004), whereas other industrialized nations have comprehensive health insurance. The relatively high expenditure on health care implies neither that the U.S. provides more health care services than other countries do (Anderson et al. 2003) nor that the U.S. ranks high on health care indicators, such as infant, neonatal, perinatal and maternal mortality rates and life expectancy (Starfield 2000; OECD 2005a). Concerning mortality rates and life expectancy, the U.S. performs worse than, for example, Canada (OECD 2005a). It is clear that the relationship between health care expenditure and health outcomes is complex (Nixon and Ulmann 2006).

The paradox of poor health records coupled with relatively high health care expenditure in the U.S. in comparison to other Western countries has been known for decades (Newhouse 1993; Fuchs 2005). There is a large amount of literature concerning health care expenditure. Health care rankings have been studied to a lesser extent.

Not only the relationship between health care spending and health outcomes, but also the explanation of health care expenditure itself is complex. The explanation is multifactoral (e.g. Reynolds 1989; Karatzas 2000; Sato 2001; Anderson et al. 2003, 2005; Sager and Socolar 2005 ) and according to Bodenheimer (2005b) varies in different historical periods.

This article integrates the dispersed studies on the topic by reducing the empirical estimates of variables contributing to the relatively high health care expenditure in the U.S. to a common denominator, GDP. It concentrates not only on factors that give an upward bias to health care expenditure, but also includes factors with a downward bias on health care expenditure in the U.S. in comparison to other countries. For example the young population and the high number of uninsured people are causes of lower health care expenditure in the U.S. than in other countries. The negative and positive effects do not balance out. Consequently health care expenditure is higher in the U.S. than in other countries.

This study quantifies the impact of different variables on health care spending as far as possible for 2002. In some cases other years are presented due to lack of empirical data. In addition to this restriction, the present study does not deal with all variables mentioned in the literature. The selection of variables is made on the basis of the available empirical studies and data. Fraud and rent seeking, for example, are not dealt with due to lack of empirical information.

The decomposition of overall spending into components that can be traced to a distinct set of explanatory factors lacks a single universally applicable, structural equation which translates the various social, cultural, demographic and economic factors driving health care spending into a nation's overall, observable health care spending per capita. Even if such an equation existed, a single equation for large countries such as the U.S. or Canada probably would not exist either, although due to history and law, Canada's provincial health systems are more homogeneous than the vastly different regions within the U.S., across which health spending per capita in any year varies more widely than per capita health spending across the OECD. Therefore, the decomposition has a high degree of uncertainty around estimated factor influences on overall spending.

To quantify the impact of different variables on health care expenditure in the U.S. in comparison to other countries, I restrict the comparison to Canada, where health care expenditure is $9.6 \%$ of GDP, i.e., 5.0\% points lower than in the U.S. in 2002 (OECD 2005a). I have chosen Canada firstly because prior to the establishment of the National Health Insurance at the end of 1960s Canada's health care system was roughly the equivalent to the U.S.'s (Newhouse 1993), and health care systems in several other countries are so different 
as to make comparisons nearly useless. ${ }^{1}$ Secondly, Canada and the U.S. are most likely to influence each other, because both countries buy many of their health-systems inputs in the same North American market area, and because medical training is interchangeable between both countries. "With a common border, a common culture, and a common capitalist penchant for profit making, Canada and the United States have forged closer economic links than any other part of independent nations in the world" (Inglehart 2000).

Notwithstanding the mutual influences and the sharing of many cultural traits, in some aspects the health care system in Canada differs nowadays significantly from the U.S. system-for example, Canada has a publicly-funded and privately-administrated health care financing system while the U.S. has a fragmented public-private health care financing system (OECD 2005a). Additionally, the Canadian health care system is characterized by universal coverage, i.e., health care is guaranteed to all of its citizens, while the U.S. is the only industrialized nation in the world that does not guarantee health care for all citizens. ${ }^{2}$

Some factors which explain the relatively high health care expenditure in the U.S. are also relevant for understanding the health status of U.S. citizens. The poor health of Americans in comparison to citizens of other countries seems mainly attributable to income, which is much more unequal in America than in other countries ${ }^{3}$ (World Bank 2005). The relationship between income and health status is supported by several studies (Starfield 2000; Bach et al. 2004; BLS 2004; CMS 2004; Lafferty 2004; Raphael et al. 2005). Ross et al. (2001) extended this relationship by incorporating segregation into their analysis. They found a relationship between increased segregation "and increased mortality for the U.S. metropolitan areas."

The present article decomposes health care expenditure into different supply and demand factors. Several demand components, such as hospital care, are excluded from the analysis, because the available data does not allow eliminating the potentially large double counting. For example wage costs are also reflected in household expenditure on hospital care.

Health care expenditure in the U.S. is $5 \%$ points of GDP higher than in Canada (for 2002). The variables listed in Table 1 , which are causing higher expenditure in the U.S. than in Canada, explain between 3.01 and $4.88 \%$ points out of the total 5 point difference (see Table 1).

The difference in health care expenditure between the U.S. and Canada is equal to 5.826.16 GDP percentage points when health care expenditure is "corrected" for the relatively high drug consumption and the uninsured in the U.S. Using this "corrected" figure as a reference point, the unexplained difference in health care expenditure is approximately $1.28(=6.16-4.88)$ to $2.81(=5.82-3.01) \%$ points of GDP. This can imply flaws in the measurement of the differences but also that other factors are relevant.

The figures in Table 1 are only rough approximations of the magnitude of the differences. There is some double counting, for example: the relatively high remuneration of health professions (Baumol's cost disease) in the U.S. is also reflected in the relatively high costs of obesity and gun injuries, and the relatively high administration costs are also counted in the

\footnotetext{
${ }^{1}$ It is to be expected that relationships at a micro level do not show up in aggregate data at a macro level when there are significant differences in health care systems. This did not withhold researchers such as for example Falaschetti (2005) and Delnoij et al. (2000) to implement large cross-country studies of health expenditure.

2 According to Birenbaum (2002), the American choice for a privately organized insurance system does not imply that America offers more choice than Canada's National Health Insurance system. In Canada patients are allowed to use any provider in the system under the term of the insurance. It resembles the American cost control through managed care, which has become the dominant form of financing and organization of American health care.

3 The distribution of income is about $20 \%$ more equal in Canada than in the United States, namely the GINI coefficient is 33 in Canada in 1998 and 41 in the USA in 2000 (World Bank 2005).
} 
Table 1 Summary determinants of health care expenditure in the U.S. in comparison with Canadian expenditure

\begin{tabular}{|c|c|c|}
\hline & Year & In $\%$ of GDP \\
\hline Difference Canada/U.S. & 2002 & -5.00 \\
\hline \multicolumn{3}{|l|}{ Supply factors } \\
\hline Investment & 2000,2002 & -0.07 to -0.10 \\
\hline Pharmaceutical prices & 2002 & -0.22 to -1.00 \\
\hline (Caused by DTC advertising & 2001 & $-0.03)$ \\
\hline Baumol's cost disease & 2002 & -0.76 \\
\hline (Net physician income & 2002 & $<-0.43)$ \\
\hline Administration costs & 2002,2003 & -0.77 to -2.61 \\
\hline Law suits & 2001, 2002 & -0.14 \\
\hline Defensive medicine & 2002 & To be specified \\
\hline (GP gatekeeper & 1996 & $-0.03)$ \\
\hline (Waiting lists & 2002 & $-0.07)$ \\
\hline \multicolumn{3}{|l|}{ Demand factors } \\
\hline Citizen's income $^{\mathrm{a}}$ & 2002 & -0.05 \\
\hline (Private funding nursing homes & 1999 & $-0.02)$ \\
\hline $\operatorname{Age}^{\mathrm{a}}$ & 2000 & 0.00 \\
\hline Insurance system & & To be specified \\
\hline Uninsured & 2001 & 0.34 to 0.68 \\
\hline Drug consumption & 2002 & -0.30 to 0.48 \\
\hline Tobacco consumption & 1992 & -0.02 \\
\hline Alcohol consumption & 1992 & -0.02 \\
\hline Obesity & 2002 & -0.16 \\
\hline Veterans & 2002 & To be specified \\
\hline Gun injuries & 2002 & $<-0.02$ \\
\hline Sum of factors causing higher expenditure in the U.S. than in Canada ${ }^{b}$ & & -3.01 to -4.88 \\
\hline Sum of factors causing lower expenditure in the U.S. than in Canada ${ }^{b}$ & & 0.82 to 1.16 \\
\hline
\end{tabular}

Legend:

${ }^{a}$ Income effect covers out-of-pocket expenditure by consumers only, i.e. it is exclusive public expenditure

${ }^{b}$ Calculation based on the biggest pharmaceutical price differential

() Not included in the summation because of double counting

expenditure on nursing homes. The sum of the different factors explaining the difference in health care expenditure excludes double counting, as far as possible.

This article starts with a snapshot of the American health care system. It is followed by a section dealing with supply factors such as investment, development of wages in relation to productivity, administration costs and other cost containing institutions in health care, such as managed care, the gatekeeping function of the general practitioner and waiting lists in elective health care. It continues with a section dealing with demand factors such as income, age, life styles and institutions such as the "peace-keeping" role of America. The final section includes a conclusion and some discussion notes.

The Canadian and the American health care system

Canada's single-payer health care system provides access to universal comprehensive coverage for medically necessary health care services. Single-payer coverage in Canada permits the use of global budgeting and rationing (Evans 2003). To provide health care the different provinces contract directly with physicians and hospitals (Health Canada 2005). This system resulted in public expenditure on health of $69.7 \%$ of total expenditure on health care in Canada in 2002. The share of private funding of health care equals $30.3 \%$ of total expenditure on health care. Private funding is made up firstly by pocket payments, secondly by private insurance, 
and thirdly by other private funds such as non-profit institutions serving households, philanthropic and charitable institutions. Their share in total health care expenditure is 15.3, 12.7 and $2.3 \%$ respectively (OECD 2005a). The U.S. in contrast has a mixed-private-public system. Private health insurance in the U.S. is tax subsidized by Federal States. According to Enthoven (2003), federal tax subsidies undermine cost-consciousness in the market for private health insurance. The employer based insurance system in the U.S. resulted in public expenditure on health care of $44.9 \%$ of total expenditure in health care. Private insurance covered $36.1 \%$ of health expenditure, while out-of-pocket payments represent $14.1 \%$, and other private funds make up 4.9\% of total health care expenditure in the U.S. in 2002 (OECD 2005a).

America's health care system is mainly privately financed through an employer based health insurance market (Rodriguez and Wiens-Tuers 2000). This employer based insurance market provides insurance coverage to about two-thirds of the population under 65 years of age. Insurance is universal for those over 65 years of age. In $198469.2 \%$ of the total population under 65 years of age obtained health insurance through their workplace, which decreased steadily (with a slight fluctuation in 1998) to 65.2 in 2002 (NCHS 2004). The insurance provided to employees at the workplace is usually part of the compensation package. There is a tax incentive for this type of coverage, because health benefits are not treated as taxable incomes. 14\% of the population is uninsured in 2002.

Health Maintenance Organizations (HMOs) ${ }^{4}$ and Preferred Provider Organizations $(\mathrm{PPOs})^{5}$ are the main providers of medical coverage. Together they insured $62 \%$ of all full-time medical benefit participants in small private enterprises (less than 100 employees) in 1996, and 73\% in medium and large establishments (100 employees or more) in 1997. This implies that most private health insurance is provided through some form of managed care organization. The remaining part has medical coverage on a fee-for-service basis (NCHS 2004).

Besides employer based insurance, medical coverage is provided by the government, through Medicare and Medicaid among others. Medicare is focused on the elderly and Medicaid is focused on the poor.

Finally, individuals can always choose private insurance themselves. This is an option chosen by some self-employed persons, but some workers also purchase insurance plans on their own from a source other than their employer (Rodriguez and Wiens-Tuers 2000).

\section{Supply side determinants of health care expenditure}

There is a wide range of studies concerning the explanation of health care expenditure: Some studies integrate two or more different variables while other studies concentrate on the analysis of separate variables. Investment, pharmaceutical prices, income in relation to productivity, administration costs, law suits, direct-to-consumer advertising, primary care and waiting lists are examined separately in the following sections.

\footnotetext{
4 "An HMO is a health care system that assumes or shares both the financial risks and the delivery risks associated with providing comprehensive medical services to a voluntarily enrolled population in a particular geographic area, usually in return for a fixed, prepaid fee. Pure HMO enrollees use only the prepaid capitates health services of the HMO panel of medical care providers. Open-ended HMO enrollees use the prepaid HMO health services but, in addition, may receive medical care from providers who are not part of the HMO panel. There is usually a substantial deductible, copayment, or coinsurance associated with use of nonpanel providers." (NCHS 2004, p. 457)

5 "A PPO is a type of medical plan where coverage is provided to participants through a network of selected health care providers (such as hospitals and physicians). The enrollees may go outside the network, but they would pay a greater percentage of the cost of coverage than within the network." (NCHS 2004, p. 475)
} 
Table 2 Total investment defined as business assets with an expected use of more than 1 year that generally are depreciated, in health care in Canada and the U.S. in 2000 and 2002

\begin{tabular}{lcccr}
\hline & 2000 Canada & 2000 U.S. & 2002 Canada & 2002 U.S. \\
\hline Per capita in US\$ purchasing power parity & $\begin{array}{c}118.54 \\
0.42\end{array}$ & $\begin{array}{r}184.14 \\
0.52\end{array}$ & $\begin{array}{r}145.23 \\
0.49\end{array}$ & $\begin{array}{r}204.71 \\
0.56\end{array}$ \\
\hline In \% of gross domestic product & & &
\end{tabular}

Source: Author's calculation based on: U.S. Census Bureau (2004b), OECD (2005b), NCHS (2004), Statistics Canada (2005)

Table 3 Medical equipment per million population in Canada (2001) and the U.S. (2002)

\begin{tabular}{lcr}
\hline & Canada & U.S. \\
\hline Computed Tomography Scanners & 9.8 & 13.1 \\
Magnetic Resonance Imaging Units & 4.2 & 8.6 \\
Radiation therapy equipment (in 1997) & 7.0 & 4.0 \\
Lithotriptors & 0.4 & 3.2 \\
Mammographs & 19.3 & 12.0 \\
\hline
\end{tabular}

Source: OECD (2005a)

Investment in highly advanced technology

Health care expenditure in the U.S. is higher than in Canada, among other things, because the U.S. invests $0.07 \%$ points of GDP more in health care business assets than Canada in 2002 (see Table 2).

U.S. invests relatively more in new technologies. This difference in capital formation is reflected in the medical equipment ratios per million population (see Table 3).

The spread of new technologies is relatively unrestrained in the U.S. and consequently many of these technologies are used to a greater extent in the U.S. than in other countries (Bodenheimer 2005a). Assuming that country differences in medical equipment ratios per capita also reflect differences in use of corresponding technologies, the figures in Table 3 suggest that conventional X-ray techniques are used more often in Canada than in the U.S. and that modern high tech techniques are used relatively less often in Canada than in the U.S.

Pharmaceutical prices

Other than investment, the difference in health care expenditure between the U.S. and Canada is explained by drug prices. U.S. drug prices were comparable to those in Canada in 1992, but rose relatively fast in the 1992-2002 period. This is indicated, among other things, by the fact that Canada's net pharmaceutical prices for 249 molecules "are $33 \%$ lower than U.S. prices net of discounts, and 40\% lower ignoring discounts," in 1999. "Netting out exchange rate movements [in the 1990s], Canadian prices are only 14\% lower than U.S. Prices" (Danzon and Furukawa 2003). Consequently, assuming that this estimate is representative for all pharmaceutical expenditure and that this estimate might be held constant, expenditure on prescription drugs is $0.22 \%$ of GDP higher in the U.S., due to the absence of price regulations, as does exist in Canada (Author's calculation based on: Danzon and Furukawa 2003; NCHS 2004). However, if Canadian pharmaceutical prices are $65 \%$ lower (unweighted average of 12 commonly used pharmaceuticals) than in the U.S., as is suggested by Burton (2003), expenditure on prescription drugs is $1.00 \%$ of GDP higher in the U.S. due to the absence of price regulations.

Although the fact that price increases for pharmaceuticals in Canada were higher in the 5 years after the Canadian regulations for generic drugs in May 1993 than price increases 
in the 6 years before the introduction (Anis et al. 2003) suggests that price regulation has no effect, it is still generally assumed that the threat of regulation of pharmaceutical prices (Ellison and Wolfram 2001) or price regulation itself explain the difference in price increases for pharmaceuticals in the U.S. and Canada.

To understand the lack of pharmaceutical price regulations in the U.S. it has to be taken into account that one of the possible disadvantages of price regulation is that it probably has a negative effect on the launch of new drugs: The number of new chemical entities launched during the mid-late 1990s is 73 in the U.S., with a mean lag of 4.2 months, and 56 in Canada, with a launch delay of 12.2 months (Danzon et al. 2003). In other words Canadian patients have poorer access to new drugs (less than 5 years in the market), compared to patients in the U.S. However, according to Angell (2004), this is not necessarily negative. Most prescriptions of expensive "new" drugs push aside the old and cheaper ones, which are already on the market. The "new" drugs are often so-called "me-too" drugs, i.e. minor variations of pharmaceuticals already on the market.

\section{Baumol's costs disease}

Besides investment and pharmaceutical prices, productivity in relation to income of health care workers also partly explains higher health care expenditure in the U.S. in comparison to Canada. Productivity in health care is difficult to improve because health care relies for a large part on a direct face to face relation between the health care worker and the patient. For example, washing a patient needs time that cannot be reduced beyond a certain point. Assuming that wages in low productivity sectors must keep up with wages in high productivity sectors, prices for labor intensive goods or services will rise relatively to prices of goods and services produced by the high productivity sectors (McPake et al. 2003). This is called Baumol's cost disease. Health care, where a large part of cost comes from staff looking after patients, is a low productivity sector. If it is true that Baumol's costs disease is overstated because the "output" used in measuring the productivity in health care fails to capture major improvements in quality (Newhouse 1993; Triplett and Bosworth 2003), focusing on one country give biased results. For example Cutler et al. (2006) show that while the cost of medical spending shot up from 1960 to 2000, largely as a result of the development and wide-spread use of new medical techniques, the cost per quality-adjusted life year decreased. However, even if the Baumol's costs disease is overstated, a comparison between countries seems to be justified. Firstly, the same measurement problems arise in the U.S. as well as in Canada. Secondly, health indicators for both males and females, such as life expectancy at birth and infant mortality rates, reveal that the quality of health care did not improve in the U.S. in comparison to Canada in the 1960-2000 period (United Nations 2005).

Although it would be better to start from 1971 to calculate the Baumol's costs disease, because the turning point in health care expenditure in the U.S. in comparison to Canada was in 1972, comparable data are not available for the whole period. Consequently, the calculation is based on the period from 1987 onwards. In 1987 expenditure on health was $2.3 \%$ points higher in the U.S. than in Canada, and in 2002 this difference was equal to 5\% points of GDP (OECD 2005a). The difference in growth of labor productivity and growth of wages and salaries in Manufacturing and Health and social work is shown in Table 4.

If wages and salaries in Health and social work had followed the wage rise in Manufacturing in the U.S. than wages and salaries in health care would have risen by $3.68 \%$ per year. This is $4.88 \%$ points per year more than the rise in productivity in Health and social work would justify, where productivity was falling. This value is assumed here to reflect 
Table 4 Growth rates (in percentages) per year of value added and of wages and salaries per full time equivalent (fte) employment, in Canada and the U.S., in the period from 1987 through 2002

\begin{tabular}{lccc}
\hline & $\begin{array}{l}1988-2002 \\
\text { Productivity per fte }\end{array}$ & $\begin{array}{l}\text { 1988-2002 Wages } \\
\text { and salaries per fte }\end{array}$ & $\begin{array}{c}\text { Difference between column 3 } \\
\text { and 2 in percentage points }\end{array}$ \\
\hline Manufacturing in the U.S. & 4.06 & 3.68 & -0.38 \\
Health and social work in the U.S. & -1.20 & 3.59 & 4.79 \\
Manufacturing in Canada & 2.38 & 3.05 & 0.67 \\
Health and social work in Canada & -0.46 & 2.88 & 3.34 \\
\hline
\end{tabular}

Source: Author's calculation based on: BEA (2005), OECD (2007, Tables 07040, 08064, 8040, 09132, 09108) $\mathrm{fte}=$ full time equivalent of employment

Table 5 Remuneration of health professions in US\$ PPP (Purchasing Power Parity), in the U.S. and Canada, in 2000 (Canada is the average of year 1999 and year 2001)

\begin{tabular}{lrr}
\hline & U.S. & Canada \\
\hline Self-employed general practitioner & 132,000 & 101,273 \\
Specialists & 200,000 & 150,554 \\
Salaried hospital nurses & 47,754 & \\
\hline
\end{tabular}

Source: OECD (2005a)

the Baumol's costs disease in American health care in the period 1987-2002. In Canada the effect is lower: it equals $3.51 \%$ points per year.

The Baumol's costs disease of $4.88 \%$ per year in health care in the U.S. in the period 1987-2002 equals $2.31 \%$ points of GDP in the U.S. in 2002. The Baumol's costs disease of $3.51 \%$ per year in health care in Canada in the period 1987-2002 equals $1.55 \%$ points of GDP in Canada in 2002. Consequently, Baumol's costs disease explains $0.76 \%$ points of the difference between the share of health care expenditure in GDP in the U.S. and Canada.

Physician's income

Baumol's cost disease can be imputed partly to physician's income. Physician's income in the U.S. is higher than in Canada (Fuchs and Hahn 1990; Anderson and Poullier 1999; Reinhardt et al. 2002). Excluding practical expenses, in 2000 the remuneration of self-employed general practitioners was US\$132,000 and US\$ PPP 101,273 in Canada (the average of the remuneration in year 1999 and 2001 is taken for Canada) (OECD 2005a) (Table 5).

Reed and Ginsburg (2003) reported an average net physician income of US\$187,000 in 1999 in the U.S. According to Fuchs and Hahn (1990), net physician income was about onethird higher in the U.S. than in Canada in the mid-1980s. Keeping both figures constant for 2002, and given that 717,549 doctors were professionally active in 2002 (NCHS 2004), this explains $0.43 \%$ of American GDP spending on health care in comparison to Canada (Author's calculation based on: NCHS 2004; Fuchs and Hahn 1990; Reed and Ginsburg 2003).

In reality the Baumol's effect attributed to physician income is lower than calculated here. The fact that physician income is lower in Canada may be because, among other things, the fees of Canadian physicians are set by a monopsonist (province governments) while those in the U.S. are more market driven.

\section{Administration costs}

Administration costs prove to be a significant variable to explain the difference in health care expenditure between the U.S. and Canada. America's health care is characterized by 
a fragmented payer system, while Canada has a single-payer system. The first has less economies of scale in administration than the latter because competition among providers of health care, on the one hand, and competition among insurers of health care on the other, result, among other things, in extra expenses in billing and administrative operations of health care providers who have to deal with 100s of payers and different rules and prices.

Overhead costs in Canada's single payer system are much lower than in the U.S.: OECD Health Data reports 72 US\$ PPP health care administration expenditure per capita in Canada in 2002 and 367 US\$ per capita in the U.S. in 2002. Total national administration costs in health care are $0.77 \%$ points of GDP higher in the U.S. than in Canada (OECD 2005a).

Whereas the OECD definition of health care administration is restricted to the activities of private insurers, central and local authorities and social security, Woolhandler et al. include besides insurance overhead costs also employers' costs of managing benefits and administration costs of hospitals, practitioners' offices, nursing homes and home care. Consequently they report much higher figures than the OECD for 1999: "In the United States, health care administration cost $\$ 294.3$ billion, or $\$ 1,059$ per capita [ . . . In Canada, health care administration cost $\$ 9.4$ billion, or $\$ 307$ per capita [. . . A After exclusions, administration accounted for $31.0 \%$ of health care expenditures in the United States, as compared with $16.7 \%$ of health care expenditures in Canada" (Woolhandler et al. 2003). Using the same broad definition, this big difference is also reported by Himmelstein et al. (2003): “The U.S. wastes more on health care bureaucracy than it would cost to provide health care to all of the uninsured. Administrative expenses will consume at least $\$ 399.4$ billion out of total health care expenditure of $\$ 1,660.5$ billion in 2003. Streamlining administrative overhead to Canadian levels would save approximately $\$ 286.0$ billion in $2003, \$ 6,940$ for each of the 41.2 million Americans who were uninsured as of 2001. This is substantially more than would be needed to provide full insurance coverage."

Using Woolhandler's et al. and Himmelstein's definition of administration costs, administration costs explain $2.61 \%$ of U.S. GDP higher spending on health care in comparison to Canada in 2003 (Author's calculation based on Himmelstein et al. 2003; OECD 2005a).

Transaction costs: law suits

Not only administration costs, i.e. costs that arise in setting up and in operating the health care system, but also transaction costs, i.e. costs that are involved in exchanging health care insurances and services, determine health care expenditure. For example, insurance companies have high costs in determining the applicant risks and in preventing moral hazard of the insured. Partly these costs are already incorporated in the previous section on administration costs. ${ }^{6}$ They will not be discussed any further. The same goes for negotiating costs for the employers (or individual applicants) and costs of monitoring how insurers treat their employees. This section is limited to the costs considering liability of health care workers.

The costs of medical liability emerged from a long history of lawsuits. Since the mid 19th century lawyers and physicians in the United States found themselves adrift as competitive agents, fiercely hustling for business of their own in the radically open professional marketplace. "Under such wide-open circumstances, suits for malpractice [...] emerged as a tempting new growth area for aggressive lawyers [...] The result was an explosion of malpractice suits" (Mohr 2000). Although one would expect that rising malpractice suits

\footnotetext{
6 Savings on administration costs in single-payer systems arise not only from economies of scale but "rather, they are due to the fact that single-payer systems do not engage in risk-selection and risk-rating of premiums. Administrative costs are lower, as the government does not devote its energies to the avoidance of high-risk individuals in the way unregulated private insurers in the U.S. do." (Flood 2003, p. 20)
} 
Table 6 American health care expenditure due to Direct Written Medical Malpractice Insurance Premiums (MMI)

\begin{tabular}{llllll}
\hline & 1980 & 1990 & 1995 & 2000 & 2002 \\
\hline GDP in billion US\$ & 2,796 & 5,803 & 7,401 & 9,825 & 10,446 \\
Premiums MMI in billion US\$ & 1.49 & 5.27 & 6.11 & 6.3 & 8.93 \\
Premium MMI in \% GDP & 0.05 & 0.09 & 0.08 & 0.06 & 0.09 \\
\hline
\end{tabular}

Source: Author's calculation based on: AIR (2003); NCHS (2004)

also results in rising insurance premiums - as suggested in the media by statements that physicians decry the rapidly rising cost of malpractice insurance, which is squeezing them out of business and running up the costs to patients-first Baicker and Chandra (2004b) "find that increases in malpractice payments made on behalf of physicians do not seem to be the driving force behind increases in premiums. Second, increases in malpractice costs (both premiums overall and the subcomponent factors) do not seem to affect the overall size of the physician workforce, although they may deter marginal entry, increase marginal exit and reduce the rural physician workforce. Third, there is little evidence of increased use of many treatments in response to malpractice liability at the state level, although there may be some increase in screening procedures such as mammography." Direct written medical malpractice insurance premiums amount to less than $1 \%$ of health costs (see Table 6).

According to Anderson et al. (2005) "The cost of defending U.S. malpractice claims, including awards, legal costs, and underwriting costs, was an estimated $\$ 6.5$ billion in $2001-0.46 \%$ of total health spending. In Canada, the [. . .] total cost [...] was $\$ 237$ million (PPP) in $2001-0.27 \%$ of total Canadian health spending." This equals $0.06 \%$ of GDP in the U.S. and $0.03 \%$ of GDP in Canada in 2001 (Author's calculation based on Anderson et al. 2005; OECD 2005a).

The costs of medical liability are higher than the direct written medical malpractice insurance premiums alone. Among other things, state costs and administration costs are involved. Nationally, malpractice costs, including malpractice insurance premium costs, defending costs and administration costs, totaled \$24.4 billion in 2002 (TillingHast/Towers Perrin 2005). These total national medical malpractice tort costs are $0.23 \%$ of GDP in 2002 (Author's calculation based on: TillingHast/Towers Perrin 2005; NCHS 2004). Assuming that the ratio of total malpractice costs in the U.S. and Canada, as reported by Anderson et al. (2005) also applies here, the total medical malpractice tort costs explain $0.14 \%$ GDP points of the higher health care expenditure in the U.S. versus Canada.

The costs mentioned above only include the explicit costs of the malpractice system. The costs do not include the cost of defensive medicine, i.e. medical tests, procedures or visits to reduce exposure to malpractice liability (Studdert et al. 2005; Kessler et al. 2006). Although these indirect costs are unknown, raw estimates are available. For example, according to president Bush (2005a) "defensive medicine drains some $\$ 60$ billion to $\$ 100$ billion from the economy [in 2003]. Defensive medicine raises medical bills for patients and increases insurance costs for employers and it takes money away that small businesses could use to invest and expand." So, defensive medicine equals $0.57-0.96 \%$ of GDP. This estimate is based on a study by Kessler and McClellan (1996). The findings have never been replicated. According to the Congressional Budget Office (2003) "Most estimates are speculative in nature, relying, for the most part, on surveys of physicians' responses to hypothetical clinical situations, and clinical studies of the effectiveness of certain intensive treatments. Compounding the uncertainty about the magnitude of spending for defensive medicine, there is little empirical 
Table 7 American health care expenditure due to direct-to-consumer advertising (DTC)

\begin{tabular}{llllll}
\hline & 1995 & 1998 & 2000 & 2001 & 2002 \\
\hline GDP in billion \$ & 7,401 & 8,782 & 9,825 & 10,082 & 10,446 \\
DTC advertising in billion \$ & 0.34 & 1.3 & 2.5 & 2.7 \\
DTC advertising in \% GDP & 0.00 & 0.01 & 0.03 & 0.03 & \\
\hline
\end{tabular}

Source: Author's calculation based on: Calfee (2002); NCHS $(2002,2004)$

evidence on the effect of medical malpractice tort controls on spending for defensive medicine and, more generally, on overall health care spending."

Transaction costs: direct-to-consumer (DTC) advertising

Next to costs of medical liability, DTC advertising is also a form of transaction cost that affects health care expenditure. The possibility of DTC advertising by pharmaceutical industries appeared in 1985, when the Food and Drug Administration (FDA) lifted its moratorium on DTC advertising. Under the constraint that DTC ads must meet the same standards as those aimed at professionals, DTC advertising gradually increased from \$12 million in 1989 to $\$ 340$ million in 1995 . In 1997 , the year that the FDA issued draft guidelines that paved the way for DTC advertising on television, the constraints had been loosened. In the wake of this policy change, DTC-advertising continued to accelerate, to $\$ 2.7$ billion in 2001 (Calfee 2002), i.e., equivalent to $0.03 \%$ of GDP (see Table 7 ).

DTC advertising costs amount to only $20 \%$ of promotional spending for all drugs. Most is targeted toward physicians (NCHS 2004). According to Scherer (2000) total prescription drug advertising and promotional outlays in the U.S. market during 1997 was estimated to be $18 \%$ of sales.

According to Angell (2004) excessive marketing expenditure is closely tied to excess me-too drugs: "For decades, the big drug companies have spent far more on "marketing and administration' [...] than on anything else. Throughout the 1990s, for example, the top 10 drug companies in the world consistently spent about $35 \%$ of sales on marketing and administration, and only 11-14\% on R\&D. [. . .] Just looking at the top 10 U.S. companies in 2002, expenditures for marketing and administration were $31 \%$ of sales, compared with only $14 \%$ for R\&D. That comes to an astonishing \$67 billion dollars of their \$217 billion in sales."

\section{Cost containment}

There are several strategies to contain health care costs, including, among other things, the strengthening of primary care practice and planning of elective health care. These devices have been implemented to a higher degree in Canada than in the U.S. (Starfield 2002). If the U.S. had implemented these productivity enhancing devices to the same degree as Canada, productivity would have been higher and consequently Baumol's cost disease would explain less of the difference in health care expenditure.

\section{Primary care}

“Throughout the 1970s, primary care was loosely defined as basic medical services offered by community practitioners. Physicians were reimbursed on a fee-for-service basis, and patients had nearly unlimited choice. Most selected generalists on the basis of convenience and familiarity, but were permitted to pursue second or specialist opinions freely" (Kanel 2002). This 
Table 8 Remuneration and "productivity" of medical doctors in 2002 in Canada and the U.S.

\begin{tabular}{|c|c|c|}
\hline & Canada & U.S. \\
\hline Remuneration specialist in US\$ PPP & 152,559 & 200,000 \\
\hline Remuneration general practitioner in US\$ PPP ${ }^{a}$ & 102,045 & 132,000 \\
\hline Surgical procedures in-patient-cases, per 1,000 population & 42 & 87.7 \\
\hline Surgical procedures per specialist & 38.18 & 60.29 \\
\hline Doctor's consultations per capitab & 6.2 & 8.9 \\
\hline Practicing specialists per capita ${ }^{\mathrm{c}}$ & 1.1 & 1.5 \\
\hline
\end{tabular}

Source: OECD (2005a)

Legend:

${ }^{\text {a }}$ US in year 2000

b Canada in year 2001

c Canada includes non-practicing physicians also

changed with the introduction of managed care, which was encouraged by the Health Maintenance Organization Act of 1973. The growth in (the number of) HMOs "accelerated in the 1970s and 1980s (from 3 million members in 1973 to more than 29 million in 1987) largely through encouragement by business interests looking for a way to control their expenditures for employee health benefits" (Institute of Medicine 1996).

In American HMO's and PPO's generalists are positioned as obligatory first-contacts for all health services. The primary task of a general practitioner in his function as gatekeeper to the health care system is the coordination of care by assessing the situation correctly, helping the patient with a proper referral and integrating the outcome of the referral into the patient's ongoing care. "This important function of the primary provider prevents fragmentation of care and the hit-or-miss nature of self referral to specialists and promotes comprehensive care, for the patient as a whole person, not merely a set of parts" (Jones 2003). Consequently, gatekeeping in primary care has the potential to reduce health care costs because it may reduce hospitalization and it may facilitate a more appropriate use of specialists (Bodenheimer and Fernandez 2005). Baicker and Chandra (2004a), ignoring possible differences in clinical training of primary care workers, conclude that health care in U.S. states with most general practitioners per capita is significantly cheaper per capita than in regions with heavier emphasis on specialist care. However, gatekeeping is also criticized because of possible negative effects: The "term gatekeeper has taken on a different meaning in describing the main function of the primary care physician: to monitor, regulate, and control the use of medical and related services by managed care organizations' patients [. . .] In this version, the gatekeeper function as carried out may not always be to the patient's benefit" (Jones 2003). Patients may view gatekeeping with suspicion because they fear that rationing (if not restricting) the use of health care resources ultimately works to the detriment of their health. This may explain some of the aversion to gatekeeping. But gatekeeping is not mandatory. If patients accept that the deviation of the least costly pathway is shifted back to them (through out-of-pocket surcharges, or co-payments) they can always opt for a more expensive pathway. So, at least in theory, even under the HMOs patients retain free choice.

Starfield (2002) ranks the U.S. in the category of health care systems with a low primary care and Canada in the category of intermediate primary care. ${ }^{7}$ One source of health care cost containment resulting from stronger primary care is the difference in remuneration of specialist and general practitioners. Remuneration for specialists is higher than for general practitioners (see Table 8).

7 "Forty percent of Americans with health insurance report that they are in gatekeeping arrangements in which their primary care physician controls their access to specialists," in 1997 (Peter 1997). 
Table 9 Productivity in Health care in Canada and the U.S., in 2002

\begin{tabular}{lrr}
\hline & Canada & U.S. \\
\hline Number of acute care beds per 1,000 population & 3.1 & 2.9 \\
Acute care bed days per capita & 1.0 & 0.7 \\
Acute care occupancy rate in \% of available beds & 86.6 & 65.7 \\
Number of practicing specialists per 1,000 population & 1.1 & 1.5 \\
Number of practicing physicians per 1,000 population & 2.1 & 2.3 \\
\hline
\end{tabular}

Source: OECD (2005a)

If a general practitioner's referral were required to visit a specialist, health care expenditure would be lowered because this would limit the number of surgical procedures and the number of specialist consults. ${ }^{8}$ This hypothesis is endorsed by a study by Pati et al. (2005): "In 1996, annual total per capita health expenditures were about $3 \%$ lower for privately insured adults enrolled in managed care gatekeeping plans than for those in indemnity plans [fee-forservice health insurance]. With nearly 105 million adults enrolled in managed care gatekeeping plans this would imply savings of about $\$ 2$ billion in national health expenditures for this group. [...] After multivariate adjustments for differences in sociodemographic and health characteristics predicted expenditures varied by about $6 \%$ between managed care gatekeeping and indemnity plan enrollees." Because 105 million adults are enrolled in managed care, and this is equal to $50 \%$ of all adults aged 20 and over, an extra $\$ 2$ billion could have been saved in 1996 if everyone was in managed care gatekeeping: this saving amounts to only 0.03 of GDP in 1996. However, this is a conservative estimate, because it only includes savings due to higher process-quality. The estimate does not include the quality benefits of heavier emphasis on primary care.

\section{Waiting lists}

Waiting lists can be the result of a policy to improve efficiency. In these cases, supply of health care is artificially scarce, i.e. it is not immediately available because supply is managed in a way to reduce underemployment of capital and labor as much as possible. Less underemployment may result in lower prices.

A positive relation between waiting lists and productivity is endorsed by Siciliani and Hurst (2005). They show that countries with long waiting list have the lowest number of acute care beds, practicing specialists and physicians per 1,000 of population. This relation is statistically significant.

Productivity in hospitals is higher in Canada than in the U.S, at least as far as indicated by the number of specialists and the number of physicians per 1,000 of population. Productivity is not higher when measured by the number of acute care beds per 1,000 of population (see Table 9).

The relatively low number of acute care beds per 1,000 of population may be explained by "the large share of activity that is carried out within the ambulatory care as opposed to the acute care sector [...] It may also be explained by the remuneration system, usually based on pay per case by Diagnosis Related Groups (DRGs) which encourages reduction in length of stay" (Siciliani and Hurst 2005).

\footnotetext{
8 According to Barbara Starfield, a gatekeeping system of primary care also offers protection from unnecessary and potentially dangerous tests and therapies. According to her, the U.S. system of having free access to high-powered specialists has negative side effects on the health status (Starfield et al. 2005).
} 
Table 10 Percentage of patients waiting for elective surgery more than 4 months for those with elective surgery in the past 2 years, in Canada and the U.S.

\begin{tabular}{lcc}
\hline & 1998 & 2001 \\
\hline Canada & 12 & 27 \\
U.S. & 1 & 5 \\
\hline
\end{tabular}

Source: Blendon et al. (2002)

Although one would expect that higher productivity rates eventually result in lower prices, Bell et al. (1998) report that there is no relationship between waiting times and prices, with the exception of a total knee replacement in the U.S.

Even though waiting lists for elective surgery ${ }^{9}$ are much shorter in the U.S. than in Canada (see Table 10), the productivity gain of waiting lists is likely to be small: "Services that typically have queues in other countries account for only $3 \%$ of U.S. health spending" (Anderson et al. 2005).

If the productivity gain of waiting lists is indicated by the $15.8 \%$ lower physician and specialists ratio per 1,000 population in Canada than in the U.S. (OECD 2005a), total productivity gain amounts to $0.07 \%$ of GDP (Author's calculation based on: OECD 2005a; NCHS 2004).

\section{Demand side determinants of health care expenditure}

Beside supply side factors there are also demand side factors that influence the amount of resources diverted to health care (Sato 2001). Demand related factors include, for example, income, age, uninsurance, fat intake and smoking.

Notwithstanding that the insurance system affects the costs of health care, as is mentioned in the paragraph on the Canadian and the U.S. health care systems, the influence of the health insurance arrangements on the costs of health care is not quantified here due to lack of data. Prices in health care are subject to public policy in Canada and consequently influence supply and demand. However, this effect cannot be compared with market equilibrium as generated in the U.S. where the market for physicians' services is not self-equilibrating in the usual sense because of supplier induced demand (Evans 1974; Nallamothu et al. 2007). Even if the data were available it would have to be corrected for Baumol's cost disease since public policy restrained the uncontrolled proliferation of Baumol's cost disease in Canada.

Income and age

Usually, aggregate health expenditures are related to measures of national income. For example the study by Poullier et al. (2002) offers robust evidence that cross-country health care expenditure variation is largely attributable to variation in GDP. However, these results may be biased by, among other things, Baumol's costs disease. That is why the present analysis sticks to Consumer Expenditure data.

Age has a concave relationship to health care consumption, i.e. newborns, young children and the elderly get the most health care. However, the age of the head of a household (consumer unit) and health care expenditure per household are related linearly. The present

\footnotetext{
${ }^{9}$ Elective surgery: planned surgery that is not an emergency requiring hospital admission within $24 \mathrm{~h}$; Emergency admission: an unplanned admission to hospital due to unexpected illness or injury that requires urgent care.
} 
Table 11 Expenditure on Health Care by total average expenditure and age in the U.S.: regression statistics on the relation between average expenditure on Health Care per consumer unit, total average expenditure per consumer unit, and age of head of the consumer unit ${ }^{\mathrm{a}}$ for each income group before taxes ${ }^{\mathrm{b}}$ per age group $^{\mathrm{c}}$, in the U.S. Consumer Expenditure Survey in 2001-2002 (data are transformed to logarithmic values)

\begin{tabular}{|c|c|c|c|c|c|}
\hline & Value & SE & $\mathrm{t}$-Value & Beta & $\operatorname{Pr}(>|\mathrm{t}|)$ \\
\hline (Intercept) & -2.9737 & 0.3001 & -9.9100 & & 0.0000 \\
\hline Total expenditure & 0.8684 & 0.0648 & 13.3975 & 0.514 & 0.0000 \\
\hline Age of head of the consumer unit & 1.3943 & 0.0707 & 19.7097 & 0.756 & 0.0000 \\
\hline $\begin{array}{l}\text { Residual standard error: } 0.0889 \\
\text { Multiple R-squared: } 0.929 \\
\text { F-statistic: } 320.8 \text { on } 2 \text { and } 49 \text { de }\end{array}$ & \multicolumn{4}{|c|}{ Residual standard error: 0.0889 on 49 degrees of freedom } & \\
\hline
\end{tabular}

Source: Author's calculation based on BLS (2004)

Legend:

a Age of head of the consumer unit: the head of the consumer unit is the first member mentioned by the respondent when asked to "Start with the name of the person or one of the persons who owns or rents the home" (BLS 2004)

$\mathrm{b}$ The distinct income groups are: less than $\$ 5,000 ; \$ 5,000-9,999 ; \$ 10,000-14,999 ; \$ 15,000-19,999 ; \$ 20,000-$ 29,999; \$30,000-39,999; \$40,000-49,999; \$50,000-69,999; \$70,000 and over

$\mathrm{c}$ The distinct age groups are: under $25,25-34,35-44,45-54,55-64$ and 65 and over

analysis focuses on household expenditure and not on expenditure per person. Health care expenditure per household proves to rise together with income and age. A regression analysis of expenditure on Health Care by income (measured by Total Average Expenditure of consumer units per income-group before taxes) and by age (measured by the age of the head of the consumer unit) ${ }^{10}$ shows that income together with age explain $93 \%$ of the spending on Health Care per income group before taxes. Spending on health care includes health insurance, medical services, drugs and medical supplies. The Betas are 0.514 and 0.765 respectively (see Table 11 ).

The finding that age of individuals is the prevailing explanation for outlays on Health Care is plausible: Firstly, "As consumption increases with income, the marginal utility of consumption falls rapidly while the value of extending life rises" in relation with aging (Hall and Jones 2004). Secondly, aging of individuals is related not only to special diseases but also to a longer period of recovery from an illness or an operation. Thirdly, different studies on expenditure on Health Care show "that the last years of life, irrespective of how long people live, are associated with high care consumption" (Batljan and Lagergren 2004). Because most people die at an age of 65 and over, and because proximity to death has a significant influence on health care outlays, it is not strange to find that expenditure on health care rises with aging of population (Seshamani and Gray 2004; Batljan and Lagergren 2004).

Since income in the U.S. is $15.5 \%$ higher than in Canada, measured in GDP per capita in Purchasing Power Parity (OECD 2005a) and the average age of the population is 1.2 years higher in Canada than in the U.S. (Author's calculation based on United Nations 2005), firstly, out-of-pocket health care expenditure in the U.S. is $0.05 \%$ of GDP higher than in Canada because of the income effect, and secondly, health care expenditure in the U.S. is $0.00 \%$ of GDP lower because of a relatively low share of aged people in population (Author's

\footnotetext{
${ }^{10}$ Health care expenditure is linearly related with income and age: the $F$ values for income and age are 28.924 and 101.127 respectively. There is no multicollinearity: the individual $t$ tests show that the partial slope coefficients are statistically different from zero. The $t$ values for income and age are 5.378 and 10.056 respectively.
} 
Table 12 Health Care Expenditure of the uninsured, in the U.S., in 2001

\begin{tabular}{lc}
\hline & 2001 \\
\hline Gross Domestic Product (GDP) in billion \$ & 10,082 \\
Health Care Expenditure uninsured in billion \$ & 98.9 \\
Number of uninsured in million persons & 44.3 \\
Health Care Expenditure of insured (including elderly) per capita in \$ & $5,382.00$ \\
Health Care Expenditure of uninsured per capita in \$ & $2,233.00$ \\
Additional Health Care Expenditure of uninsured when insured privately & $33.9-68.7$ \\
$\quad$ or publicly in billion \$ & $0.34-0.68$
\end{tabular}

Source: Author's calculation based on: NCHS (2004) and Hadley and Holahan (2003a,b)

calculation based on: NCHS 2004; U.S. Census Bureau 2004a; BLS 2004). ${ }^{11}$ The difference in the age structure of the Canadian and American population is so small that this does not result in a noticeable impact on the differential spending of the two countries.

The finding that income and health care expenditure are positively related is not selfevident. Poverty negatively affects the health status of individuals (Ross et al. 2001; Lopez 2004) and consequently the poor are more in need of health care than the rich. Therefore, it is plausible to expect that lower income groups spend more on health care than higher income groups. However, this is not supported by the empirical data. Consequently other variables are at stake. The positive relation is likely a reflection of the institution that access to sophisticated health care, expensive well-trained physicians and well-funded hospitals is highly influenced by income. Additionally, aged people can be rich. As far as expenditure on health care of the higher incomes is involved, the positive relation with age is indicated by for example charges to "rich" residents in nursing homes, i.e. those residents with own income or family support as the primary source of payment. These charges to rich residents are $12.7 \%$ higher than average charges to residents in nursing homes in 1999. Higher charges to the rich equals $0.02 \%$ of GDP in 1999 (Author's calculation based on NCHS 2004).

The uninsured

Health care consumption of the uninsured is U.S. \$98.9 billion in 2001 (Hadley and Holahan 2003a). Every uninsured person spends U.S. $\$ 3,149$ less on health care, on average, than an insured person in 2001. If the uninsured were insured (privately or publicly) additional health care expenditure would be $0.34-0.68 \%$ of GDP higher than reported by the National Center for Health Statistics (see Table 12).

Minorities with the lowest income have the highest uninsurance rates, (NCHS 2004) and the uninsured receive less care and are more likely to suffer adverse consequences due to delayed or postponed care. In consequence, access and quality problems in health care disproportionately affect people at the bottom of the income ladder and this is reflected in heir health status: Black or African American minorities prove to have lower life expectancy and higher infant mortality rates than the white Americans (NCHS 2004).

\footnotetext{
11 Out-of-pocket expenditures

$=3.374473=-2.9737+(0.8684 * 4.609349)+(1.3943 * 1.682145)$

Out-of-pocket expenditures with income effect

$=3.310959=-2.9737+(0.8684 * 4.536209)+(1.3943 * 1.682145)$

Out-of-pocket expenditures with income and age effect

$=3.329554=-2.9737+(0.8684 * 4.536209)+(1.3943 * 1.695482)$

[Absolute values are US\$ 2,368; US\$2,046; US\$ 2,136 respectively].
} 
According to the U.S. Census Bureau more than one third of the uninsured in 2001 live in households with annual incomes below US \$25,000, almost one-third live in households with annual incomes above $\$ 50,000$ and one in five live in households earning more than $\$ 75,000$ annually. The growth in the number of uninsured between 2000 and 2001 was highest among family households earning more than $\$ 75,000$ per year. This suggests that there is a high degree of free choice about whether to have coverage.

"Using the income of health insurance units vs. household incomes changes the distribution of the newly uninsured markedly" (Holahan et al. 2003). The difference between both indicators is that the health insurance unit is an individual or an entire family of dependents while the household income also includes income of "sub-families or unrelated persons that reside there. For example, the household could include more than one nuclear family, as well as extended family relatives, e.g. grandparents, cousins, aunts, and uncles of the family maintaining the household. Since a household includes all those who share a housing unit, the incomes of several unrelated individuals sharing an apartment for example, would also be counted together. These combined incomes for a single household are then assigned to each person living in that household as if they were fully available for them to use" (Holahan et al. 2003). The use of "health insurance unit" income, instead of household income, as a reference unit for analyzing changes in insurance coverage between 2000 and 2001, results in the biggest growth in the number of uninsured among units with incomes less than two times the poverty level. Because both measures of income result in a growth in the number of uninsured among people in the highest income bracket in 2001, it is clear that some free choice still exists. Considering uninsurance among the lowest income brackets, it is likely that this is not always by choice: Firstly, because employer based insurance plans are not portable, employees lose their coverage as soon as they leave or lose their employment. Secondly, some of the uninsured simply cannot afford the cost of coverage.

\section{Cultural and behavioral variables}

Besides income and age, "social interactions, culture, economic institutions, or the consumption choices or well-being of others" also affect consumption (Ackerman 1997). Specific factors influencing demand for health care in the U.S. are, among other things, the relatively high rate of adults considered as overweight or obese (OECD 2005a) and the "peacekeeping" role of the U.S. in the world. The latter is likely to have resulted in a relatively high number of physically and psychologically wounded war veterans (for example those who served in Vietnam and Iraq) and consequently in higher health care expenditure.

Aging of population and drug consumption

Money value of drug consumption proves to increase especially with age (Beta 0.881) (see Table 13).

Given the positive relationship between money value of drug consumption and age, one might expect lower drug consumption in America than in Canada because the age structure of the population in America is relatively young in comparison to Canada's. However, pharmaceutical prices in the U.S, are higher than in Canada. A comparison of drug consumption between both countries requires a correction for price differences. Lower drug consumption in the U.S. in comparison to Canada occurs if the price difference between the U.S. and Canada is bigger than $33.3 \%$. The section on pharmaceutical prices suggests that the differential is somewhere between 14 and $65 \%$. Total spending at current prices is $0.52 \%$ points of 
Table 13 Money value of drug consumption, income and age, in the U.S., in 2001 (data are transformed to logarithmic values)

\begin{tabular}{|c|c|c|c|c|c|}
\hline & Value & SE & $\mathrm{t}$-Value & $\operatorname{Pr}(>|\mathrm{t}|)$ & Beta \\
\hline (Intercept) & -2.1099 & 0.3351 & -6.2966 & 0.0000 & \\
\hline Income & 0.4824 & 0.0724 & 6.2511 & 0.0000 & 0.272 \\
\hline Age & 1.5984 & 0.0790 & 20.2349 & 0.0000 & 0.881 \\
\hline \multicolumn{5}{|c|}{ Residual standard error: 0.09928 on 49 degrees of freedom } & \\
\hline
\end{tabular}

Source: Authors' calculation based on BLS (2004)

Table 14 Consumption of some health influencing items per capita, in the U.S., in 2002

\begin{tabular}{llc}
\hline & Canada & U.S. \\
\hline Fat intake grams per day & 146.2 & 156.5 \\
Calories intake per day & 3,589 & 3,774 \\
Fruit and vegetables in kilos & 250.5 & 238.0 \\
Sugar in kilos & 42.2 & 30.2 \\
Protein intake in grams per day & 105.0 & 114.0 \\
Tobacco in grams per day (aged 15 and over) & $1,432^{\mathrm{a}}$ & 1,588 \\
Alcohol in liters & $7.8^{\mathrm{a}}$ & 8.3 \\
\hline
\end{tabular}

Source: OECD (2005a)

Legend: a 2001

GDP higher in America than in Canada in 2002. Price differences of 14, 33.3, and 65\% respectively result in a differential in the volume of health care spending on pharmaceuticals of 0.30 , 0.00 , and $-0.48 \%$ points of GDP respectively (Author's calculation based on OECD 2004).

(Un)healthy lifestyle

Medical literature (e.g. Chick 1998) proves that there is a relationship between bad habits associated with lower classes (such as heavy drinking) and mortality. For example, higher social class is associated with light/moderate drinking, while heavy drinkers tend to be found in lower income households. Heavy drinking is associated with increased mortality.

Americans seem to do relatively bad concerning fat intake, calories intake, fruit and vegetables consumption, tobacco intake and alcohol consumption (see Table 14).

The figures on obesity in Canada are 53.9\% lower than in the U.S. in 2002: $14.1 \%$ (the arithmetic median of the data in 2001 and 2003) of the Canadian population and 30.6 of the American population were obese in 2002 (OECD 2005a).

Estimates of costs of obesity-related diseases vary from approximately $6 \%$ of the national health care expenditure in 1995 (Wolf 1998) to 9.1\% of total annual U.S. medical expenditure in 1998 (Finkelstein et al. 2003; Bhattacharya and Bundorf 2005), and approximately $10 \%$ in 2002 (WIN 2005; NCHS 2004). However, a recent study reports a more conservative estimate: Between 1987 and 2002, the share of private health spending attributable to obesity soared more than 10 -fold, from $\$ 3.6$ to $\$ 36.5$ billion (Thorpe et al. 2005). $\$ 36.5$ Billion equals $1.24 \%$ of private health spending in 2002 (NCHS 2004). This conservative estimate of obesity related expenditure results in a higher expenditure on health care in the U.S. than in Canada of $0.16 \%$ points of GDP.

Finally, the figures in Table 14 indicate that tobacco and alcohol consumption is slightly higher in the U.S. than in Canada. Although this could be due to the U.S. health care system 
Table 15 Possible tobacco and alcohol consumption related mortality per 100,000 population, in the U.S., in 2001

\begin{tabular}{lcr}
\hline & Canada & U.S. \\
\hline Chronic liver diseases and cirrhosis & 6.9 & 9.5 \\
Malignant neoplasms of trachea, bronchus and lung & 47.0 & 49.7 \\
Acute myocardial infarction & 48.6 & 50.3 \\
\hline
\end{tabular}

Source: OECD (2005a)

being more effective in detecting and curing cancers, mortality caused by tobacco and alcohol consumption is also higher in the U.S. than in Canada (see Table 15). This finding indicates that there are relatively more heavy drinkers in America. Mortality rates would have been lower if there were relatively more light drinkers in the U.S.

The direct health care costs related to alcohol and tobacco in Canada were $0.58 \%$ of GDP in 1992 (Single et al. 1998). If alcohol consumption and tobacco consumption in Canada were as high as in the U.S. in 2001 then Canadian direct health care costs would have been approximately $0.02 \%$ of GDP higher for alcohol and tobacco consumption respectively (Author's calculation based on Single et al. 1998; OECD 2005a).

Veterans and deaths and injuries due to firearms

Finally, a large number of veterans and a large number of injuries due to firearms are two possible factors contributing to the relatively high health care expenditure in the U.S. in comparison to other countries.

The American Veterans Administration (AVA) coordinates American health care expenditure for veterans. This organization provides hospital care for military veterans through the use of global budgets (Feldman and Lobo 1997). It is an example of a health care delivery system that enhances primary care (Ferrer et al. 2005). Health care expenditure by The Department of Veterans Affairs accounts for $2.6 \%$ of total Federal spending for HIV-related activities in 2002 and for 3.5\% of total mental health expenditure on 2000 (NCHS 2004). These shares are higher than the proportion of veterans in total population, which is about $0.9 \%$. This indicates that HIV-related expenditure and mental health spending are relatively high for veterans. Total health care expenditure by the Department of Veteran Affairs health care expenditure is only $0.22 \%$ of GDP in 2002 (NCHS 2004; see also Cowman et al. 2004). Because these figures do not include all health care expenditure for veterans it cannot be concluded that the health care expenditure of veterans is higher than average expenditure. This makes a comparison with the health care expenditure of veterans in Canada meaningless.

As to health care expenditure in relation to firearms injuries there is only data for the U.S. An estimated 30,424 firearms deaths ${ }^{12}$ (Miniño etal. 2006) and 58.841 nonfatal firearms injuries $^{13}$ (NCIP\&C 2005) were reported in 2002. The mean medical cost per injury is about $\$ 23,000$. Given the number of injuries and the mean medical cost, gunshot injuries in the U.S. produced $\$ 2.1$ billion in medical costs in 2002. This equals $0.02 \%$ of American GDP (Author's calculation based on Cook et al. 1999; U.S. Census Bureau 2004b).

12 Of these deaths, 762 were unintentional, 17,108 were suicides, 11,829 were homicides, 243 were undetermined and 300 were related to legal interventions or war (Miniño et al. 2006, p. 9).

13 Of these injuries, 17,579 were unintentional, 3,295 were self-harm, 37,321 were assaults, and 646 were related to legal interventions (NCIP\&C 2005). 


\section{Conclusion and discussion}

Supply factors seem to explain a larger part of health care expenditure than demand factors. The difference in health care expenditure between the U.S. and Canada can mainly be attributed to administration costs and Baumol's costs disease (see Table 1). The impact of other factors may be small in relation to total health care expenditure, but most of them are still substantial since every $0.01 \%$ of GDP equals a little more than 1 billion US\$.

The different factors that explain the difference in health care expenditure primarily seem to be a manifestation of the national cultures. The U.S. has a strong belief in individualism and limited government, while Canada attaches great value "to communal obligations and a robust public sector" (Inglehart 2000). American culture ${ }^{14}$ is more concerned about responsibility for one's own life or in other words about "microeconomic efficiency", "freedom of choice for consumers" and "appropriate autonomy for providers" than that it is concerned about "adequacy and equity in access", "income protection" (that is, "patients should be protected from payments for health that represent catastrophic threats to their income or wealth") and "macroeconomic efficiency" (that is, cost control) (Hurst 1991). In other words, the market is the dominating governance structure in U.S. health care while regulation of health care is the more dominating governance structure in Canada. These features are most prominently reflected in the insurance arrangements: the employer based insurance arrangements in the U.S. and the single-payer arrangement in Canada. From this point of view, the relatively high health care expenditure in the U.S. in comparison to other industrialized countries is primarily a matter of choice of governance structure. Higher health care expenditures related to the choice of governance structure in U.S. health care system include: firstly, high administrative costs that result from the differentiated payment system; secondly, the relatively high remuneration of health care specialists; and thirdly the relatively high pharmaceutical prices.

Not only national differences in expenditures but also the relatively ranking on health care indicators and the fact that millions of Americans are uninsured seem to be manifestations of the overarching cultures. One of the elements of U.S. culture is that people are responsible for their own income and wealth. Big income differentials are related to a culture of free choice and own responsibilities. Because poverty negatively affects the health status of individuals, higher income differentials in the U.S. relative to Canada, make the U.S. have a relatively lower ranking on some health care indicators than Canada, and may well offset the effects of the superior care made possible by the high tech investment.

The paradox of high health care expenditure and low ranking on health care indicators persisting for decades seems to be rooted in the overarching culture, resulting in an unequal distribution of income. The relatively unequal distribution of income in the U.S. seems to be the crux behind the paradox. Improvements in microeconomic efficiency are likely to reduce,

\footnotetext{
14 The American medical system reflects the hallmarks of American culture. Firstly, American culture seems to be characterized by a strong confidence in the blessings of individual economic independence. It is anchored in the assumption that an individual, as far as economic matters are involved, knows better what is good for him or her than someone else or whatever institute/authority. Attached to this assumption is the conviction that everybody has an own responsibility in preparing him or herself for the challenges of life in a free society. This includes among other things that health insurance is an individual responsibility. Secondly, American culture seems to be qualified by an optimistic outlook on the future. Williamson (1985, p. 38) has formulated this as follows "Workers and their families are irrepressible optimists. They are taken in by vague assurances of good fait, by legally unenforceable promises and by their hopes for the good life. Tough-minded bargaining in its entirety never occurs or, if it occurs, comes too late." Both hallmarks of American culture are summarized concisely by President Bush in his inauguration of 2005: "By making every citizen an agent of his or her own destiny, we will give our fellow Americans greater freedom from want and fear, and make our society more prosperous and just and equal" (Bush 2005b).
} 
but not solve, the paradox but will not solve the paradox as long as the U.S. keeps track with free choice, competition etc. as benchmarks of health care.

Acknowledgements I would like to thank Baruch College (New York) for providing research facilities in September and October 2005, two anonymous referees of this journal and Max Heywood (Utrecht University) for their thorough reading and useful comments and suggestions. Naturally, the usual disclaimer applies.

Open Access This article is distributed under the terms of the Creative Commons Attribution Noncommercial License which permits any noncommercial use, distribution, and reproduction in any medium, provided the original author(s) and source are credited.

\section{References}

Ackerman, F. (1997). Consumed in theory: Alternative perspectives on the economics of consumption. Journal of Economic Issues, 31(3), 651-664.

AIR (Americans for Insurance Reform). (2003). Medical malpractice insurance: Stable losses/unstable rates 2003. http://www.insurancereform.org/StableLosses2003F.pdf (Accessed January 30th, 2005).

Anderson, G. F., \& Poullier, J.-P. (1999). Health spending, access, and outcomes: Trends in industrialized countries. Health Affairs, 18(3), 178-192.

Anderson, G. F., et al. (2003). It's the prices, stupid: Why the United States is so different from other countries. Health Affairs, 22(1), 89-105.

Anderson, G. F., et al. (2005). Health spending in the United States and the rest of the industrialized world. Health Affairs, 24(4), 903-914.

Angell, M. (2004). Excess in pharmaceutical industry. Canadian Medical Association Journal, 171(12), 14511453.

Anis, A. H., et al. (2003). Lowering generic drug prices; less regulation equals more competition. Medical Care, 41(1), 135-141.

Bach, P. B., et al. (2004). Primary care physicians who treat Blacks and Whites. The New England Journal of Medicine, 351(6), 575-584.

Baicker, K., \& Chandra, A. (2004a). Medicare spending, the physician workforce, and beneficiaries' quality of care. Health Affairs, Web Exclusive, April, W4:184-W4:197.

Baicker, K., \& Chandra, A. (2004b). The effect of malpractice liability on the delivery of health care. NBER Working Paper 10709. Cambridge, MA: National Bureau of Economic Research.

Batljan, I., \& Lagergren, M. (2004). Inpatient/outpatient health care costs and remaining years of life-effect of decreasing mortality on future acute health care demand. Social Science \& Medicine, 59(12), 2459-2466.

BEA (Bureau of Economic Analysis). (2005). http://www.bea.gov/bea/pn/GDPbyInd_VA_SIC.xls (Accessed September 20th, 2005), http://www.bea.gov/bea/pn/GDPbyInd_VA_NAICS.xls (Accessed September 20th, 2005).

Bell, C. M., et al. (1998). Shopping around for hospital services; a comparison between the United States and Canada. Journal of the American Medical Association, 279(13), 1015-1017.

Bhattacharya, J., \& Bundorf, M. K. (2005). The incidence of the healthcare costs of obesity. NBER Working Paper 11303. Cambridge, MA: National Bureau of Economic Research.

Birenbaum, A. (2002). Wounded profession: American medicine enters the age of managed care. Westport, CT: Praeger/Greenwood.

Blendon, R. J., et al. (2002). Inequities in health care: A five-country survey. Health Affairs, 21(3), 182-191.

BLS (Bureau of Labor Statistics, United States Department of Labor). (2004). Consumer Expenditures in 2002 , report 974.

Bodenheimer, T. (2005a). High and rising health care costs. Part 2: Technologic innovation. Annals of Internal Medicine, 142(11), 932-937.

Bodenheimer, T. (2005b). High and rising health care costs. Part 3: The role of health care providers. Annals of Internal Medicine, 142 (12, Part 1), 996-1002.

Bodenheimer, T., \& Fernandez, A. (2005). High and rising health care costs. Part 4: Can costs be controlled while preserving quality? Annals of Internal Medicine, 143(1), 26-31.

Burton, D. (2003). As U.S. prices continue to increase, seniors look elsewhere for their pharmaceutical prescription drugs. http://www.house.gov/hensarling/rsc/doc/Burton101303.pdf (Accessed March 12th, 2007).

Bush, G. W. (2005a). President discusses medical liability reform, January 5th, 2005.

Bush, G. W. (2005b). President sworn-in to second term, Inauguration speech January 20th, 2005. 
Calfee, J. E. (2002). Public policy issues in direct-to-consumer advertising of prescription drugs. Washington, DC: American Enterprise Institute.

Chick, J. (1998). Alcohol, health and the heart: Implications for clinicians. Alcohol \& Alcoholism, 33(6), 576-591.

CMS (Centers for Medicare \& Medicaid Services). (2004). Your medicare benefits, publication no. CMS10116. Baltimore, MD: U.S. Department of Health and Human Services, Centers for Medicare \& Medicaid Services.

Congressional Budget Office. (2003). H.R. 5. help efficient, accessible, low-cost, Timely Healthcare (Health) Act of 2003. March 10, 2003. http://www.cbo.gov/ftpdocs/40xx/doc4098/hr5ec.pdf (Accessed February 12th, 2007).

Cook, P. J., et al. (1999). The medical costs of gunshot injuries in the United States. Journal of the American Medical Association, 282 (5), 447-454.

Cowman, C., et al. (2004). National health expenditures, 2002. Health Care Financing Review, 25(4), 143-166.

Cutler, D. M., Rosen, A. B., \& Vijan, S. (2006). The value of medical spending in the United States, 1960-2000. The New England Journal of Medicine, 355, 920-927.

Danzon, P. M., \& Furukawa, M. F. (2003). Prices and availability of pharmaceuticals: Evidence from nine countries. Health Affairs, Web Exclusive, October, W3:521-W3:536.

Danzon, P. M., et al. (2003). The impact of price regulation on the launch of new drugs. NBER Working Paper no. 9874. Cambridge, MA: National Bureau of Economic Research.

Delnoij, D., et al. (2000). Does general practitioner gatekeeping curb health care expenditure? Journal of Health Services, Research \& Policy, 5(1), 22-26.

Ellison, S. F., \& Wolfram, C. (2001). Pharmaceutical prices and political activity. NBER Working Paper 8482. Cambridge, MA: National Bureau of Economic Research.

Enthoven, A. C. (2003). Employment-based health insurance is failing: Now what? Health Affairs, Web Exclusive, May, W3:237-W3:249.

Evans, R. G. (1974). Supplier-induced demand: Some empirical evidence and implications. In M. Perlman (Ed.), The economics of health and medical Care. London: Macmillan.

Evans, B. (2003). Equity, social capital and financing in health systems. University of British Columbia. Presentation to the Joint RACP/HSRAANZ Conferences, Melbourne.

Falaschetti, D. (2005). Aggregate health expenditures, national income, and institutions for private property available from the SSRN Electronic Paper Collection.

Feldman, R., \& Lobo, F. (1997). Global budget and excess demand for hospital care. Economics of Health Care Systems, 6(2), 187-196.

Ferrer, R. L., et al. (2005). The essential role of generalists in health care systems. Annals of Internal Medicine, 142(8), 691-699.

Finkelstein, E. A., et al. (2003). National medical spending attributable to overweight and obesity: How much, and who is paying? Health Affairs, Web Exclusive, May, W3:219-W3:226.

Flood, C. (2003). International health care reform. Routledge: London.

Fuchs, V. R. (2005). Editorial; health care expenditures reexamined. Annals of Internal Medicine, 143(1), 76-78.

Fuchs, V. R., \& Hahn, J. S. (1990). How does Canada do it? A comparison of expenditures for physicians' services in the United States and Canada. The New England Journal of Medicine, 323(13), 884-890.

Hadley, J., \& Holahan, J. (2003a). Who pays and how much? The cost of caring for the uninsured. Health Affairs, Web Exclusive, W3:66-W3:81.

Hadley, J., \& Holahan, J. (2003b). Covering the uninsured: How much would it cost? Health Affairs, Web Exclusive, W3:250-W3:265.

Hall, R. E., \& Jones, C. I. (2004). The value of life and the rise in health spending. NBER Working Paper Series, Working Paper 10737. Cambridge MA: National Bureau of Economic Research.

Health Canada. (2005). Canada's health care system. HC Pub: 5912.

Himmelstein, D. U., et al. (2003). Administrative waste in the U.S. health care system in 2003: The cost to the nation, the states and the district of Columbia, with state-specific estimates of potential savings. Cambridge MA: The Division of Social and Community Medicine, Department of Medicine, The Cambridge Hospital and Harvard Medical School; Washington, DC: The Public Citizen Health Research Group.

Holahan, J., et al. (2003). The new middle-class of uninsured Americans. Is it real? Issues Paper, March 2003 Kaiser Commission on Medicaid and the Uninsured.

Hurst, J. W. (1991). Reforming health care in seven European nations. Health Affairs, 10(3), 7-21.

Inglehart, J. K. (2000). Revisiting the Canadian health care system. The New England Journal of Medicine, 342(26), 2007-2012.

Institute of Medicine. (1996). Primary care: America's health in a new era. Washington, DC: National Academies Press. 
Jones, S. (2003). An introduction to the U.S. health care system. New York: Springer Publishing.

Kanel, K. T. (2002). Adult primary care. In J. S. Sanfilippo \& C. L. Robinson (Eds.), Risk management handbook for healthcare professionals (pp. 19-36). London, New York: Parthenon Publishers.

Karatzas, G. (2000). On the determination of the US aggregate health care expenditure. Applied Economics, 32(9), 1085-1099.

Kessler, D., \& McClellan, M. (1996). Do doctors practice defensive medicine. Quarterly Journal of Economics, 111(2), 353-390.

Kessler, D., et al. (2006). Effects of the medical liability system in Australia, the UK and the USA. The Lancet, $368(7), 240-246$.

Lafferty, W. (2004). Healing, medical care, and health service organizations. The Journal of Alternative and Complementary Medicine, 10 (Supplement 1), S-141-S-146.

Lopez, R. (2004). Income inequality and self-rated health in US metropolitan areas: A multi-level analysis. Social Science \& Medicine, 59(12), 2409-2419.

McPake, B., et al. (2003). Health economics; an international perspective. London: Routledge.

Miniño, A. M., et al. (2006). Deaths: Injuries 2002. National Vital Statistics Reports, National Center for Health Statistics, 54(10), 1-125.

Mohr, J. C. (2000). American medical malpractice litigation in historical perspective. Journal of the American Medical Association, 283(13), 1731-1737.

Nallamothu, K., et al. (2007). Opening of specialty cardiac hospitals and use of coronary revascularization in medicare beneficiaries. Journal of the American Medical Association, 297(9), 962-968.

NCHS (National Center for Health Statistics). (2002). Health, United States, 2002; with chartbook on trends in the health of Americans. Publication no. 2002-1232. Hyattsville, MD: United States Department of Health and Human Services.

NCHS (National Center for Health Statistics). (2004). Health, United States, 2004; with chartbook on trends in the health of Americans. Publication no. 2004-1232. Hyattsville, MD: United States Department of Health and Human Services.

NCIP\&C (National Center for Injury Prevention and Control). (2005). Overall firearm gunshot nonfatal injuries and rates per 100,000 in WISQARS nonfatal injury reports. http://webappa.cdc.gov/sasweb/ncipc/ nfirates2001.html (Accessed September 12th, 2005).

Newhouse, J. P. (1993). An iconoclastic view of health cost containment. Health Affairs, 12(Supplement), 152-172.

Nixon, J., \& Ulmann, P. (2006). The relationship between health care expenditure and health outcomes. The European Journal of Health Economics, 7(1), 7-18.

OECD. (2004). OECD health data 2004, frequently requested data (3rd ed.), released 09/24/2004.

OECD. (2005a). Health data 2005, fourteenth OECD electronic database on health systems, date of release June 2005, last update 04/26/2005.

OECD. (2005b). National accounts, Vol. 1.

OECD. (2007). National accounts and historical statistics; national accounts II.

Pati, S., et al. (2005). Health expenditures for privately insured adults enrolled in managed care gatekeeping vs. indemnity plans. American Journal of Public Health, 95(2), 286-291.

Poullier, J.-P., et al. (2002). Patterns of global health expenditures: Results for 191 countries. Discussion paper No 51. World Health Organization.

Raphael, D., et al. (2005). Researching income and income distribution as determinants of health in Canada: Gaps between theoretical knowledge, research practice, and policy implementation. Health Policy, 72(2), 217-232.

Reed, M. C., \& Ginsburg, P. B. (2003). Behind the times: Physician income, 1995-99. Data Bulletin No 23. Center for Studying Health System Change.

Reinhardt, U. E., et al. (2002). Cross-national comparisons of health systems using OECD data 1999. Health Affairs, 21(3), 169-181.

Reynolds, R. L. (1989). The delivery of medical care and institutional change. Journal of Economic Issues, 23(1), 215-229.

Rodriguez, C. B., \& Wiens-Tuers, B. A. (2000). Access, choices, and household income: A comparison of health insurance coverage for standard and nonstandard workers. Journal of Economic Issues, 34(2), 499-508.

Ross, N. A., et al. (2001). Income segregation, income inequality and mortality in North American metropolitan areas. GeoJournal, 53(2), 117-124.

Sager, A., \& Socolar, D. (2005). Health costs absorb one-quarter of economic growth, 2000-2005: Recent federal report unintentionally obscures massive rise; physicians' decisions key to controlling cost. Data Brief No. 8 . 
Sato, Y. (2001). Comparative analysis of health care costs in Japan and the United States: A simulation of productivity and savings behavior. Japan and the World Economy, 13(4), 429-454.

Scherer, F. M. (2000). The pharmaceutical industry. In A. J. Culyer \& J. P. Newhouse (Eds.), Handbook of health economics. Amsterdam: Elsevier.

Seshamani, M., \& Gray, A. (2004). Ageing and health-care expenditure: The red herring argument revisited. Health Economics, 13(4), 303-314.

Siciliani, L., \& Hurst, J. (2005). Explaining waiting-time variations for elective surgery across OECD countries. OECD Economic Studies, no. 38, 2004/1 (pp. 95-123). Paris: OECD.

Single, E. L., et al. (1998). The economic costs of alcohol, tobacco and illicit drugs in Canada, 1992; research report. Addiction, 93(7), 991-1006.

Starfield, B. (2000). Is US health really the best in the world? Journal of the American Medical Association, 284(4), 483-485.

Starfield, B. (2002). Policy relevant determinants of health: An international perspective. Health Policy, 60(3), 201-218.

Starfield, B., et al. (2005). Comorbidity and the use of primary care and specialist care in the elderly. Annals of Family Medicine, 3(3), 215-222.

Statistics Canada. (2005). CANSIM, table 029-0005 and catalogue no. 61-205-XIB.

St. Peter, R. F. (1997). Gatekeeping arrangements in widespread use. Data Bulletin No. 07, Center for Studying Health System Change.

Studdert, D. M., et al. (2005). Defensive medicine among high-risk specialist physicians in a volatile malpractice environment. Journal of the American Medical Association, 293(21), 2609-2617.

Thorpe, K. E., et al. (2005). Impact of rising disease prevalence on private health insurance spending. Health Affairs, Web Exclusive, June, W5:317-W5:325.

TillingHast/Towers Perrin. (2005). U.S. tort costs: 2004 Update; trends and findings on the cost of the U.S. tort system. http://www.towersperrin.comf (Accessed August 10th, 2005).

Triplett, J. E., \& Bosworth, B. P. (2003). Productivity measurement issues in service industries: 'Baumol's Disease' has been cured. Economic Policy Review, 9(3), 23-33.

United Nations. (2005). World population prospects: The 2004 revision population database (Population by five-year age-group and sex). New York: Department of Economic and Social Affairs, Population Division. http://esa.un.org/unpp/index.asp?panel'2 (Accessed January 30th, 2007).

U.S. Census Bureau. (2004a). Global population profile 2002. Washington, DC: U.S. Government Printing Office.

U.S. Census Bureau. (2004b). Statistical abstract of the United States: 2004-2005 (142nd ed.). Washington, DC: U.S. Government Printing Office.

Williamson, O. E. (1985). The economic institutions of capitalism. New York: The Free Press.

WIN (Weight-control Information Network, U.S. Department of Health and Human Services). (2005). Statistics related to overweight and obesity. http://win.niddk.nih.gov/statistics/ (Accessed January 21st, 2005).

Wolf, A. (1998). What is the economic case for treating obesity? Obesity Research, 6(Supplement 1), 2S-7S.

Woolhandler, S. T., et al. (2003). Cost of health care administration in the United States and Canada. New England Journal of Medicine, 349(8), 768-775.

World Bank. (2005). World development indicators database. 